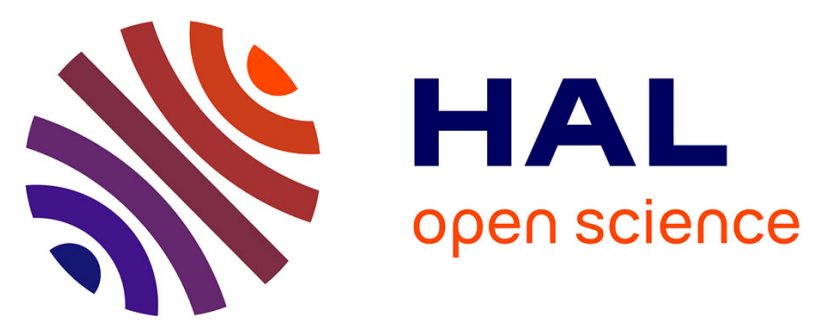

\title{
Lower limb muscle injury location shift from posterior lower leg to hamstring muscles with increasing discipline-related running velocity in international athletics championships
}

\author{
Pascal Edouard, Karsten Hollander, Laurent Navarro, Lilian Lacourpaille, \\ Antonio Morales-Artacho, Christine Hanon, Jean-Benoît Morin, Sébastien Le \\ Garrec, Pedro Branco, Astrid Junge, et al.
}

\section{- To cite this version:}

Pascal Edouard, Karsten Hollander, Laurent Navarro, Lilian Lacourpaille, Antonio Morales-Artacho, et al.. Lower limb muscle injury location shift from posterior lower leg to hamstring muscles with increasing discipline-related running velocity in international athletics championships. Journal of Science and Medicine in Sport, 2021, 24 (7), pp.653-659. 10.1016/j.jsams.2021.02.006 . hal-03297167

\section{HAL Id: hal-03297167 https://hal.science/hal-03297167}

Submitted on 26 Jul 2021

HAL is a multi-disciplinary open access archive for the deposit and dissemination of scientific research documents, whether they are published or not. The documents may come from teaching and research institutions in France or abroad, or from public or private research centers.
L'archive ouverte pluridisciplinaire HAL, est destinée au dépôt et à la diffusion de documents scientifiques de niveau recherche, publiés ou non, émanant des établissements d'enseignement et de recherche français ou étrangers, des laboratoires publics ou privés. 
Original Research:

2

3 Lower limb muscle injury location shift from posterior lower leg to hamstring muscles 4 with increasing discipline-related running velocity in international athletics 5 championships

7 Running head: Lower limb muscle injury location in athletics

8

9 Pascal Edouard ${ }^{1,2,3}$, Karsten Hollander ${ }^{4}$, Laurent Navarro ${ }^{5}$, Lilian Lacourpaille ${ }^{6}$, Antonio J. Morales-Artacho $^{7}$, Christine Hanon ${ }^{7,8}$, Jean-Benoît Morin ${ }^{1,9}$, Sébastien Le Garrec ${ }^{10}$, Pedro 11 Branco $^{3}$, Astrid Junge ${ }^{4,11}$, Gaël Guilhem ${ }^{7}$

From:

${ }^{1}$ Inter-university Laboratory of Human Movement Science (LIBM EA 7424), University of Lyon, University Jean Monnet, F-42023. Saint Etienne, France

$16{ }^{2}$ Department of Clinical and Exercise Physiology, Sports Medicine Unit, University Hospital 17 of Saint-Etienne, Faculty of Medicine, Saint-Etienne, France

$18{ }^{3}$ European Athletics Medical \& Anti Doping Commission, European Athletics Association 19 (EAA), Lausanne, Switzerland

$20 \quad{ }^{4}$ Medical School Hamburg, Hamburg, Germany

$21{ }^{5}$ Mines Saint-Etienne, Univ Lyon, Univ Jean Monnet, INSERM, U 1059 Sainbiose, Centre CIS, 22 F-42023 Saint-Etienne France

$23{ }^{6}$ University of Nantes, Movement, Interactions, Performance, MIP, EA 4334, F-44000 Nantes, 24 France 
$1{ }^{7}$ French Institute of Sport (INSEP), Laboratory Sport, Expertise and Performance (EA 7370),

2 Paris, France

$3{ }^{8}$ French Athletics Federation (FFA), Paris, France

$4{ }^{9}$ Sports Performance Research Institute New Zealand (SPRINZ), Auckland University of

5 Technology, Auckland, New Zealand

$6{ }^{10}$ French Institute of Sport (INSEP), Paris, France

$7 \quad{ }^{11}$ Swiss Concussion Center, Schulthess Clinic Zürich, Switzerland

8

9

\section{Correspondence to}

11 Pascal Edouard, MD PhD, Department of Clinical and Exercise Physiology, Sports Medicine

12 Unit, IRMIS, Campus Santé Innovations, University Hospital of Saint-Etienne, 42055 Saint-

13 Etienne cedex 2, France. Tel.: +33 674574 691; Fax numbers: +33 477127 229; E-mail:

14 Pascal.Edouard42@gmail.com.

15

16

17 Word count of manuscript (excluding abstract and references): 2902

18 Word count of the Abstract: 250

19 Number of references: 30

20 Number of Tables: 1

21 Number of Figures: 2

24 Funding: No specific funding was received for the present study. The present study was 25 conducted in the context of the FULGUR project funded by the French Research Agency in the 
1 perspective of the Paris 2024 Olympic and Paralympic Games in collaboration with French

2 Federations of Athletics, Rugby and Ice Sports, Universities of Nantes, Côte d'Azur, Savoie

3 Mont Blanc, Jean Monnet Saint-Etienne, Saclay, the Mines Saint-Etienne, the CEA and the

4 CNRS. The University Jean Monnet Saint-Etienne and the French Institute of Sport (INSEP)

5 are partners of the French-speaking network ReFORM, recognized as a Research Centre for the

6 Prevention of Injury and Illness and the Protection of Athletes by the Olympic Committee

7 (IOC). As a member of the IOC Medical Research Network, ReFORM has received funding

8 from the IOC to establish long-term research program on the prevention of injuries and illnesses

9 in sport for the protection of athlete health.

Competing Interest: None declared.

12

Ethics approval: The study protocol was reviewed and approved by the Saint-Etienne

University Hospital Ethics Committee (Institutional Review Board: IORG0007394; IRBN742020/CHUSTE).

Scientific contributions of each author:

Pascal Edouard, MD, PhD: substantial contributions to the conception and design of the study, collection, analysis and interpretation of data, developing the figures, drafting, writing and revising of the manuscript, and approval of the final version to be published.

Karsten Hollander, MD, PhD: substantial contributions to the analysis and interpretation of data, developing the figures, writing and revising of the manuscript, and approval of the final version to be published. 
1 Laurent Navarro, PhD, Ing: substantial contributions to the analysis and interpretation of

2 data, developing the figures, revision of the manuscript, and approval of the final version to be 3 published.

4 Lilian Lacourpaille, PhD: substantial contributions to the interpretation of data, writing,

5 revision of the manuscript, and approval of the final version to be published.

6 Antonio J Morales-Artacho, PhD: substantial contributions to the developing the figures, 7 revision of the manuscript, and approval of the final version to be published.

8 Christine Hanon, PhD: substantial contributions to the interpretation of data, revision of the 9 manuscript, and approval of the final version to be published.

Jean-Benoît Morin, PhD: substantial contributions to the revision of the manuscript, and 11 approval of the final version to be published.

12 Sébastien Le Garrec, MD: substantial contributions to the approval of the final version to be published.

Pedro Branco, MD: substantial contributions to the data collection and interpretation of data, revision of the manuscript, and approval of the final version to be published. Astrid Junge, PhD: substantial contributions to the interpretation of data, writing and revision of the manuscript, and approval of the final version to be published. Gaël Guilhem, PhD: substantial contributions to the conception of the study, interpretation of data, writing and revision of the manuscript, and approval of the final version to be published. 


\section{ABSTRACT}

2 Objective: To analyse the rates of lower limb muscle injuries in athletics disciplines requiring

3 different running velocities during international athletics championships.

4 Design: Prospective total population study.

5 Methods: During 13 international athletics championships (2009 - 2019) national medical

6 teams and local organizing committee physicians daily reported all newly incurred injuries using the same study design, injury definition and data collection procedures. In-competition lower limb muscle injuries of athletes participating in disciplines involving running (i.e. sprints, hurdles, jumps, combined events, middle distances, long distances, and marathon) were analysed.

Results: Among the 12,233 registered athletes, 344 in-competition lower limb muscle injuries were reported (36\% of all in-competition injuries). The proportion, incidence rates and injury burden of lower limb muscles injuries differed between disciplines for female and male athletes. The most frequently injured muscle group was hamstring in sprints, hurdles, jumps, combined events and male middle distances runners (43\% to $75 \%$ ), and posterior lower leg in female middle distances, male long distances, and female marathon runners (44\% to 60\%). Hamstring muscles injuries led to the highest burden in all disciplines, except for female middle distance and marathon and male long distance runners. Hamstring muscles injury burden was generally higher in disciplines requiring higher running velocities, and posterior lower leg muscle injuries higher in disciplines requiring lower running velocities.

Conclusions: The present study shows discipline-specific injury location in competition context. Our findings suggest that the running velocity could be one of the factors that play a role in the occurrence / location of muscle injuries. 
1 Keywords: Sports injury prevention; injury surveillance; epidemiology; track and field; top2 level athletes; muscle injury risk. 


\section{INTRODUCTION}

2 The muscles of the lower limb are the most frequently injured structure in athletics disciplines

3 involving running. ${ }^{1}$ During international athletics championships, lower limb muscle injuries

4 (LLMI) represented $\sim 90 \%$ of all muscle injuries and $\sim 40 \%$ of all injuries. ${ }^{2}$ During such major

5 events, lower injury rates were associated with performance success in a national team (i.e.

6 more medals and gold medals). ${ }^{3}$ Thus, reduction of LLMI represents one of the possibilities to

7 improve success in major athletics championships.

8

9 The muscles of the lower limb play a major role in running performance by generating the forces needed to increase or maintain running velocity. ${ }^{4,5}$ The contribution of muscle groups 11 differs between slow and fast running velocities: plantarflexor muscles (i.e. soleus, 12 gastrocnemius, tibialis posterior, peroneus and toes flexors) contribute more at slower

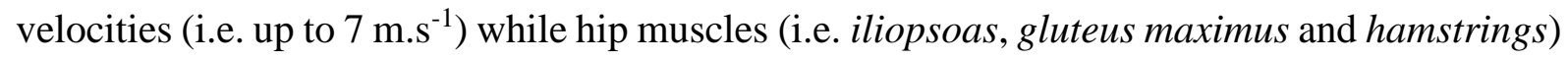
contribute more at faster velocities (i.e. greater than 7 m.s $\left.{ }^{-1}\right) .{ }^{4}$ To achieve faster velocities, the hamstring muscles are particularly involved in the forward horizontal force production during the sprint acceleration, ${ }^{6}$ and performed the largest amount of positive and negative work. ${ }^{7}$ The amount of negative work sustained by muscle fascicle may condition the functional consequences of muscle ultrastructure damage induced by muscle contraction. ${ }^{8}$ In this context, we hypothesised that injured muscle groups generally vary between disciplines with different running velocities (Supplementary Table 2), and that predominantly muscles involved to generate running velocity will be injured. Muscles acting as plantar flexor may therefore be more frequently injured in athletics disciplines requiring slower running velocity, and muscles acting on the hip joint as flexor or extensor more frequently in disciplines requiring faster running velocity. We particularly made this hypothesis for the two most frequent injured muscles in international athletics championships: ${ }^{2}$ hamstring and posterior lower leg muscles 
1 as hip extensors and plantar flexors, respectively. Such detailed information is of importance to

2 better understand injury mechanisms, and thus, develop discipline-specific injury risk reduction

3 strategies, and eventually to improve performance.

4

5 Therefore, we aimed to analyse the rates and characteristics of LLMI, and especially hamstring

6 and posterior lower leg muscles injuries, between athletics disciplines requiring different running velocities (Supplementary Table 2) in order to determine whether the muscle groups mainly involved in generating the running velocity are more often injured during international athletics championships.

\section{METHODS}

We conducted a prospective total population study. In-competition LLMI of elite athletes participating in sprints, hurdles, jumps, combined events, middle distances, long distances, and marathon (Supplementary Table 2) during 13 international athletics championships were analysed: World Outdoor Championships 2009, 2011, 2013; European Outdoor Championships 2012, 2014, 2016, 2018; World Indoor Championships 2014; and European Indoor Championships 2011, 2013, 2015, 2017, and 2019. The 13 championships comprised 69 competition days (19 days for the 6 indoor and 50 for the 7 outdoor championships). There was no patient and public involvement.

All data were collected using the same study design, injury definition and data collection procedures, previously described in detail..$^{2,9-13}$ The injury database from a previous study was extended. ${ }^{2}$ Only injuries were included that $i$ ) occurred in sprints, hurdles, jumps, combined events, middle distances, long distances, and marathon, ii) occurred during competitions 
1 (injuries during warm-up were considered as in-competition injuries; training injuries were

2 excluded), iii) affected the "lower limb” (i.e. hip, groin, thigh (subcategories: quadriceps,

3 hamstring, others), knee, lower leg (subcategories: posterior lower leg, others), Achilles tendon,

4 ankle, foot), and iv) were classified as "strain / muscle rupture / tear" or "muscle cramps or

5 spasm”. LLMI were grouped for analyses into hip \& groin, quadriceps, hamstring, other thigh,

6 posterior lower leg, other lower leg (i.e. injury location at the "lower leg other" or "Achilles

7 tendon”), and others (i.e. injury location at the "knee”, “ankle” or “foot”). All injury reports in

8 the database were anonymous.

9

Since running velocities were not measured at the exact time of the injury, data from the world

records and the 8 (or 6 for some indoor events) top-ranked athletes during the 13 included championships (except for jumps) were used to determine the range and order of disciplinerelated required running velocities from sprints to marathon (Supplementary Table 2).

A descriptive analysis of LLMI rates and characteristics was performed by calculating i) numbers and percentages of injuries and of estimated time-loss injuries, ii) incidence rates ${ }^{14}$ (i.e. number of injuries per 1000 registered athletes and per 1000 starts (with 95\% confidence intervals)), ${ }^{11,12,15,16}$ and iii) burden of injuries (i.e. total estimated number of days of absence from sport per 1000 registered athletes), ${ }^{17}$ for the total population, and separately for each sex ${ }^{10}$ and discipline. ${ }^{11}$ For injury severity, the mean number of days estimated to result in absence from sport ( \pm standard deviation (SD)) was calculated. To test our hypothesis on hamstring and posterior lower leg muscles injuries and athletics disciplines, comparisons of the incidence rates and the burden of injuries i) between hamstring vs. posterior lower leg muscles injuries for each discipline, and ii) between disciplines with sprints as reference (discipline with the highest required running velocity (Supplementary Table 2)) for hamstring and posterior lower leg 
1 muscles injuries, were performed using relative risk (with 97.5\% confidence intervals (97.5\%

$2 \mathrm{CI}$ ), due to the two comparisons). Significance was accepted at $\mathrm{p}<0.05$, with corrections for 3 multiple tests.

\section{RESULTS}

A total of 5705 female and 6528 male athlete entries, and 11588 starts for female and 13537 starts for male athletes in sprints, hurdles, jumps, combined events, middle distances, long distances, and marathon were registered during the 13 championships. On average, $86.8 \%$ of all national medical teams, covering $82.7 \%$ of registered athletes, participated in the injury surveillance project, and returned $94.2 \%$ of the report forms. The completeness of injury data used in the present study reached $98.9 \%$. No athlete refused to allow his/her data to be used for scientific research.

In total, 947 in-competition injuries were recorded in sprints, hurdles, jumps, combined events, middle distances, long distances, and marathon, of which 344 were classified as LLMI (36.3\%; Supplementary Table 3). The number and percentage of LLMI differed between disciplines for both female and male athletes (Figure 1, Supplementary Table 3 and Figure 3). The most frequently injured muscle group was hamstring in sprints, hurdles, jumps, combined events and male middle distances runners, and posterior lower leg in female middle distances, male long distances, and female marathon runners (Figure 1, Supplementary Table 3 and Figures 3). Figure 1 shows an increase in the proportion of hamstring muscles injuries and a decrease in the proportion of posterior lower leg muscles injuries with increasing running velocity elicited by the disciplines. 
1 In-competition injury incidence rates differed between disciplines and were significantly higher

2 for hamstring than for posterior lower leg muscles in female sprinters, and male sprinters and

3 hurdlers (Figures 1 and 2, Table 1 and Supplementary Table 4). Hamstring muscles injury

4 incidence rates were significantly higher in sprints than in jumps, middle distances and long

5 distances for male athletes (Figures 1 and 2, Table 1 and Supplementary Table 4). Posterior

6 lower leg muscles injury incidence rates were significantly lower in sprints than in combined

7 events, middle and long distances and marathon for female athletes (Figures 1 and 2, Table 1

8 and Supplementary Table 4).

9

Information in relation to estimated time loss in sport after injury was available for $92.2 \%$ of

11 the reported LLMI $(n=317)$. Time-loss injuries represented $68.0 \%$ and $68.2 \%$ of all incompetition LLMI in female and male athletes, respectively (Supplementary Table 5). Hamstring muscles injuries led to the highest burden in all disciplines, except for female middle distance and marathon, and male long distance runners (Figure 2 and Supplementary Table 5). Injury burden resulting from hamstring muscles injuries was significantly higher than from posterior lower leg muscles injuries in sprints, combined events and long distances for female athletes, and in sprints, hurdles, jumps, combined events for male athletes (Table 1, Figure 2 and Supplementary Table 5). Injury burden resulting from hamstring muscles injuries was significantly higher in sprints than in hurdles, jumps, combined events, and middle distances for female athletes, and in sprints than in jumps, middle distance and marathon for male athletes, and significantly lower in sprints than in long distances for female athletes, and in sprints than in hurdles for male athletes (Table 1, Figure 2 and Supplementary Table 5). Injury burden resulting from posterior lower leg muscles injuries was significantly lower in sprints than in combined events, middle distances and marathon for female athletes, and in sprints than 
1 in long distances and marathon for male athletes, and significantly higher in sprints than in 2 jumps and middle distances for male athletes (Table 1, Figure 2 and Supplementary Table 5).

\section{DISCUSSION}

The main findings of the present study confirmed our hypothesis that the location of LLMI varied between athletics disciplines requiring different running velocities. Higher frequency, incidence and burden of hamstring muscles injuries were reported in disciplines requiring higher running velocities. Posterior lower leg muscles injuries were in general the most frequent type, with higher incidence and burden, only in disciplines requiring slower running velocities.

Muscle contribution to horizontal force production has been shown to vary with running

13 velocity. ${ }^{4,5}$ Running velocity can basically be described as the product of stride length and frequency. ${ }^{18}$ For increasing running velocities up to about $7 \mathrm{~m} . \mathrm{s}^{-1}$ the predominant component is increasing stride length, which is achieved through higher contribution of the plantarflexor muscles. ${ }^{4}$ This may expose plantarflexor muscles to increased load in middle and long distances and marathon, and could be one of the factors that can explain the higher reported injury proportion, incidence rates and injury burden of posterior lower leg muscles injuries in these disciplines. Hip flexor and extensor muscles injuries did exist in such disciplines since these muscles contribution was not zero, ${ }^{4}$ and some velocity peak may occur at higher running velocities or during sudden changes of velocity for example during passing manoeuvres or final sprints.

23 For further acceleration above $7 \mathrm{~m}^{-1} \mathrm{~s}^{-1}$ a $25 \%$ increase of stride frequency occurs, predominantly performed by the hip flexor and extensor muscles. ${ }^{4}$ In accordance, a shift was described from plantarflexor to hip muscles contribution with running velocity increase. ${ }^{4}$ Of all the major lower 
1 limb muscle groups, this strategy is typically resulting from gluteus maximus, iliopsoas and

2 hamstrings actions which exhibit an increase in the amplitude of muscle-tendon unit length

3 changes and mechanical work during terminal swing phase when running velocity progresses

4 toward maximal sprinting. ${ }^{4,7,19}$ Specifically, hamstring muscle fibres withstand larger strains

5 towards maximal sprint running velocity. ${ }^{20}$ Such exposition of human muscle fibres to

6 substantial strain and negative work has been proposed to strongly influence the magnitude of

7 muscle damage. ${ }^{8,21}$ Hence, the accumulation of damage due to repeated strides may in turn

8 leave exercised muscles more prone to injury. ${ }^{21}$ This has been interpreted as hamstring muscles

9 increased injury susceptibility with increased running velocity, ${ }^{20}$ which is consistent with our epidemiological results. For velocities above $7.0 \mathrm{~m} . \mathrm{s}^{-1}$, the absolute contribution of 11 plantarflexor muscles to face the vertical support are similar than for lower velocities, ${ }^{4}$ which could explain the fact that there are still posterior lower leg muscle injuries in disciplines eliciting fast velocities.

The magnitude of muscle fibers stretch-shortening velocity may also play a role. When sprinting close to maximal velocity, athletes reach a mean knee extension and hip flexion angular velocity about $\sim 1200^{\circ} . \mathrm{s}^{-1}$ and $\sim 600^{\circ} . \mathrm{s}^{-1}$, respectively, over one running gait cycle. ${ }^{22}$ Although the viscoelastic properties of the muscle-tendon unit can contribute to mitigate muscle strain as movement velocity increases,${ }^{23}$ the decrease in muscle force generating capacities with velocity may contribute to increase the risk of injury. ${ }^{24}$ Such decrease in force-generating capacity may be exacerbated in the presence of damage of muscle ultrastructure due to high amount of negative work performed by muscle fibers. ${ }^{8,21}$ These biomechanical hypotheses are in line with our findings showing higher proportion, incidence rate and burden of hamstring muscle injuries in athletics disciplines requiring higher running velocity. Changes in running technique may also play an important role for running performance and to mitigate the exposition of lower limb muscle to injury. ${ }^{4-6}$ Such strategy is compromised during near 
1 maximal and maximal sprints due to limited solutions (i.e. muscle coordination) to achieve such

2 running velocities. ${ }^{4}$ Alternatively, fatigue may play a role as the muscles mainly involved to

3 generate running velocity will exhibit muscle fatigue early, leading to an acute decrease in

4 force-generating capacity, which could consequently lead to a higher risk of injury. ${ }^{24}$ Given

5 that a $i$ ) unbalanced contributions of hamstring muscles to joint torque may accelerate the

6 occurrence of fatigue ${ }^{25}$ and ii) a deficit in muscle endurance may be associated with an

7 increased risk of sustaining a recurring hamstring injury, ${ }^{26}$ earlier occurrence of fatigue could

8 contribute to explain the incidence of hip muscle injuries at high running velocity. ${ }^{27}$

9

The present study extends previous findings regarding the importance of muscle injuries in 11 international athletics championships. ${ }^{2,9-11}$ Muscle injuries accounted for about a third of all 12 injuries during international athletics championships, with proportions varying between disciplines. This makes reduction of muscle injuries the first challenge for athlete's health protection, and also for performance improvement, given the close relationships between health, injury and performance in athletics. $3,16,28$

Hamstrings were the most frequently injured muscles in the majority of the disciplines involving running ( $>50 \%$ of muscle injuries in disciplines involving high running velocities: sprints, hurdles, jumps and combined events). This extends previous findings ${ }^{2}$ placing the hamstring muscle injury as the predominant injury diagnosis in international athletics championships. This confirms the need to further improve our understanding of such injuries specifically in the context of athletes, and in turn develop injury risk reduction measures targeting muscle injuries in athletics.

24 Strengths and limitations of the injury data collection have been discussed previously. . $^{2,9-11,13}$ 
1 The major strength is the large database allowing in-depth analysis including detailed visual

2 representations of data. For example, Figure 2 combines the presentation of data from different

3 nature: sex (binary data), injury location (categorial), discipline (categorical), injury rate (real

4 number) and injury burden (real number). Categorical data are shown on the $\mathrm{x}$ - and $\mathrm{y}$-axis.

5 Binary data is presented with a specific half-disc shape allowing the direct visual comparison

6 of male and female athletes. The size and colour of the half-disc show continuous values, so

7 they are used to visualise injury rate and burden. The main objective is to propose a

8 representation allowing to observe directly and at best all these data combined, naked eye, in

9 an easy-to-read way.

A specific limitation of the present study is that exact running velocities were not measured at

the time of injury. The order of required running velocities for the different athletics disciplines was determined based on the average performance of the top athletes in these disciplines during the 13 championships and the world records, except for jumps where we used an extrapolation. No information on the exposure to running and running velocities could be recorded. The present study provided a descriptive analysis of the number, proportion, incidence and burden of LLMI according to the athletics disciplines and their estimated required running velocities. The potential association between running velocity and the occurrence of injuries, as well as a causal relationship could not be analysed. Our analyses were not adjusted to other confounding factors that can influence muscle injury occurrence (e.g. age, history of previous injuries) ${ }^{29,30}$, and that can play a role on running performance and mechanics (e.g. training regimens, running technique, individual properties of muscle-tendon, genetics). More in-depth investigations are therefore required to understand the complex relationship between running discipline mechanics and LLMI occurrence. 
1 Although our results describe differences in LLMI between athletics disciplines and associated

2 running velocities, further studies should elucidate the mechanisms of LLMI. Is there any causal

3 relationship between running velocity and injury occurrence within a discipline? Does the

4 injury location differ within a discipline (e.g. sprints) between periods of low-velocity high-

5 force (e.g. start in sprint) and fast velocity low-force movements (e.g. last part of the sprint)?

6 Do differences in running velocity between female and male athletes explain the lower rates of

7 reported overall and hamstring muscle injuries in female compared to male athletes? ${ }^{2}$ Are there

8 any relationships between the level of muscle activation, constraint and/or force during running

9 and injury risk?

Our findings suggest that specific muscles mainly involved in generating specific forces to achieve a given running velocity seem to be those predominantly injured in elite athletes. These muscles may be strong enough to sustain discipline-specific demands but not to reduce injury risk. Since stronger muscles can protect from injury by absorbing more energy and compensating from potential lower force-generating capacity from synergist muscles, ${ }^{24}$ it could be of interest to target strengthening of these muscles within the specific context of the required running velocity. This provides additional arguments for preventive interventions to be specific for each athletic discipline, according to biomechanical requirement and injury mechanisms. As the same muscles are primary drivers of running performance and injury prevention, LLMI risk reduction in athletics disciplines involving running should be seen as a win-win performance-prevention approach. ${ }^{3,16}$ Such arguments should be also used to heighten awareness of athletes and coaches to injury prevention approach.

\section{CONCLUSIONS}


1 “Tell me your athletics discipline, I will tell you what injury you are at risk”. Our present study

2 shows differences in the location of LLMI between athletics disciplines requiring different

3 running velocities in elite athletes during competition. Our findings suggest that the running

4 velocity could be one of the factors that play a role in the occurrence / location of muscle

5 injuries. The in-depth information linking injury risk and running biomechanics should be

6 regarded when developing discipline-specific injury risk reduction strategies.

9 Practical implications:

- The location of lower limb muscle injuries varied between athletics disciplines requiring different running velocities.

- Higher frequency, incidence and burden of hamstring muscle injuries were reported in disciplines requiring higher running velocities.

- Posterior lower leg muscle injuries were the most frequent type, with higher incidence and burden only in disciplines requiring lower running velocities.

- Predominantly injured muscles seem to correspond to the specific muscles mainly involved to generate running velocities achieved in corresponding athletics discipline.

- Lower limb muscle injury risk reduction in athletics disciplines involving running should be considered as discipline- and velocity-specific, that may contribute to the

\section{REFERENCES}


Started and We Are on Track! New Stud Athl 2015; 30(3):69-78.

22 Edouard P, Branco P, Alonso J-M. Muscle injury is the principal injury type and hamstring muscle injury is the first injury diagnosis during top-level international athletics championships between 2007 and 2015. Br J Sports Med 2016; 50(10):619630. Doi: 10.1136/bjsports-2015-095559.

3 Edouard P, Richardson A, Navarro L, et al. Relation of team size and success with injuries and illnesses during eight international outdoor athletics championships. Front Sport Act Living 2019:31 July 2019. Doi: doi: 10.3389/fspor.2019.00008.

4 Dorn TW, Schache AG, Pandy MG. Muscular strategy shift in human running: dependence of running speed on hip and ankle muscle performance. J Exp Biol 2012; 215(13):2347-2347. Doi: 10.1242/jeb.075051.

5 Hamner SR, Delp SL. Muscle contributions to fore-aft and vertical body mass center accelerations over a range of running speeds. J Biomech 2013; 46(4):780-787. Doi: 10.1016/j.jbiomech.2012.11.024.

6 Morin J-B, Gimenez P, Edouard P, et al. Sprint acceleration mechanics: the major role of hamstrings in horizontal force production. Front Physiol 2015; 6:404.

7 Schache AG, Dorn TW, Blanch PD, et al. Mechanics of the human hamstring muscles during sprinting. Med Sci Sports Exerc 2012; 44(4):647-658. Doi: 10.1249/MSS.0b013e318236a3d2.

8 Guilhem G, Doguet V, Hauraix H, et al. Muscle force loss and soreness subsequent to maximal eccentric contractions depend on the amount of fascicle strain in vivo. Acta Physiol 2016; 217:152-163. Doi: 10.1111/apha.12654.

9 Feddermann-Demont N, Junge A, Edouard P, et al. Injuries in 13 international Athletics championships between 2007-2012. Br J Sports Med 2014; 48(7):513-522. Doi: 10.1136/bjsports-2013-093087. 
110 Edouard P, Feddermann-Demont N, Alonso JM, et al. Sex differences in injury during

2 top-level international athletics championships: surveillance data from 14 championships between 2007 and 2014. Br J Sports Med 2015; 49(7):472-477. Doi: 10.1136/bjsports-2014-094316.

11 Edouard P, Navarro L, Branco P, et al. Injury frequency and characteristics (location, type, cause and severity) differed significantly among athletics ('track and field') disciplines during 14 international championships (2007-2018): implications for medical service planning. Br J Sports Med 2020; 54(3):159-167.

Timpka T, Alonso J-M, Jacobsson J, et al. Injury and illness definitions and data collection procedures for use in epidemiological studies in Athletics (track and field): consensus statement. Br J Sports Med 2014; 48(7):483-490. Doi: 10.1136/bjsports2013-093241.

Edouard P, Branco P, Alonso JM, et al. Methodological quality of the injury surveillance system used in international athletics championships. J Sci Med Sport 2016; 19(12). Doi: 10.1016/j.jsams.2016.03.012.

14 Nielsen RO, Debes-Kristensen K, Hulme A, et al. Are prevalence measures better than incidence measures in sports injury research? Br J Sports Med 2019; 53(7):396-397. Doi: 10.1136/bjsports-2017-098205.

Junge A, Engebretsen L, Alonso JM, et al. Injury surveillance in multi-sport events: the International Olympic Committee approach. Br J Sports Med 2008; 42:413-421. Doi: 10.1136/bjsm.2008.046631.

2216 Edouard P, Navarro L, Pruvost J, et al. In-competition injuries and performance success in combined events during major international athletics championships. J Sci Med Sport 2020:In press.

Bahr R, Clarsen B, Derman W, et al. International Olympic Committee consensus 
statement: methods for recording and reporting of epidemiological data on injury and illness in sport 2020 (including STROBE Extension for Sport Injury and Illness Surveillance (STROBE-SIIS)). Br J Sports Med 2020:1-18. Doi: 10.1136/bjsports2019-101969.

18 Hamner SR, Seth A, Delp SL. Muscle contributions to propulsion and support during running. J Biomech 2010; 43(14):2709-2716. Doi: 10.1016/j.jbiomech.2010.06.025.

19 Hegyi A, Goncalves BAM, Finni T, et al. Individual Region- and Muscle-specific Hamstring Activity at Different Running Speeds. Med Sci Sport Exerc 2019; 51(11):2274-2285. Doi: 10.1249/MSS.0000000000002060.

20 Fiorentino NM, Rehorn MR, Chumanov ES, et al. Computational Models Predict Larger Muscle Tissue Strains at Faster Sprinting Speeds. Med Sci Sport Exerc 2014; 46(4):776-786. Doi: 10.1249/MSS.0000000000000172.

21 Butterfield TA. Eccentric Exercise In Vivo : Strain-Induced Muscle Damage and Adaptation in a Stable System. Exerc Sport Sci Rev 2010; 38(2):51-60.

22 Higashihara A, Ono T, Kubota JUN, et al. Functional differences in the activity of the hamstring muscles with increasing running speed. J Sports Sci 2010; 28(August):10851092. Doi: 10.1080/02640414.2010.494308.

23 Monte A, Baltzopoulos V. Gastrocnemius Medialis and Vastus Lateralis in vivo muscle-tendon behaviour during running at increasing speeds. Scand J Med Sci Sport 2020; 30(7):1163-1176. Doi: 10.1111/sms.13662.

24 Garrett WE, Safran MR, Seaber A V, et al. Biomechanical comparison of stimulated and nonstimulated skeletal muscle pulled to failure. Am J Sport Med 1987; 15(5):448454.

25 Avrillon S, Guilhem G, Barthelemy A, et al. Coordination of hamstrings is individual specific and is related to motor performance. J Appl Physiol 2020; 125:1069-1079. 
Doi: 10.1152/japplphysiol.00133.2018.

226 Schuermans J, Van Tiggelen D, Danneels L, et al. Susceptibility to Hamstring Injuries in Soccer A Prospective Study Using Muscle Functional Magnetic Resonance Imaging. Am J Sport Med 2016; 44(5):1276-1285. Doi: 10.1177/0363546515626538.

27 Edouard P, Mendiguchia J, Lahti J, et al. Sprint Acceleration Mechanics in Fatigue Conditions: Compensatory Role of Gluteal Muscles in Horizontal Force Production and Potential Protection of Hamstring Muscles. Front Physiol 2018; 9(November):112. Doi: 10.3389/fphys.2018.01706.

Raysmith BP, Drew MK. Performance success or failure is influenced by weeks lost to injury and illness in elite Australian track and field athletes: A 5-year prospective study. J Sci Med Sport 2016; 19(10):778-783. Doi: 10.1016/j.jsams.2015.12.515.

Green B, Pizzari T. Calf muscle strain injuries in sport: A systematic review of risk factors for injury. Br J Sports Med 2017; 51(16):1189-1194. Doi: 10.1136/bjsports2016-097177. injury ( HSI ) - A 2020 systematic review and meta- - analysis of risk factors for index and recurrent HSI in sport. Br J Sports Med 2020:1-10. Doi: 10.1136/bjsports-2019100983. 


\section{Figure legends}

2

3 Figure 1 Percentage of in-competition lower limb muscle injuries (with lower and upper

4 limits of 95\% of confidence interval; in ordinate axis) and number of in-competition lower limb

5 muscles injuries per 1000 registered athletes (i.e. incidence rate; size of the dots), according to

6 athletics disciplines (in abscissa axis) and sex (female and male athletes), during 13

7 international athletics championships 2009-2019.

8

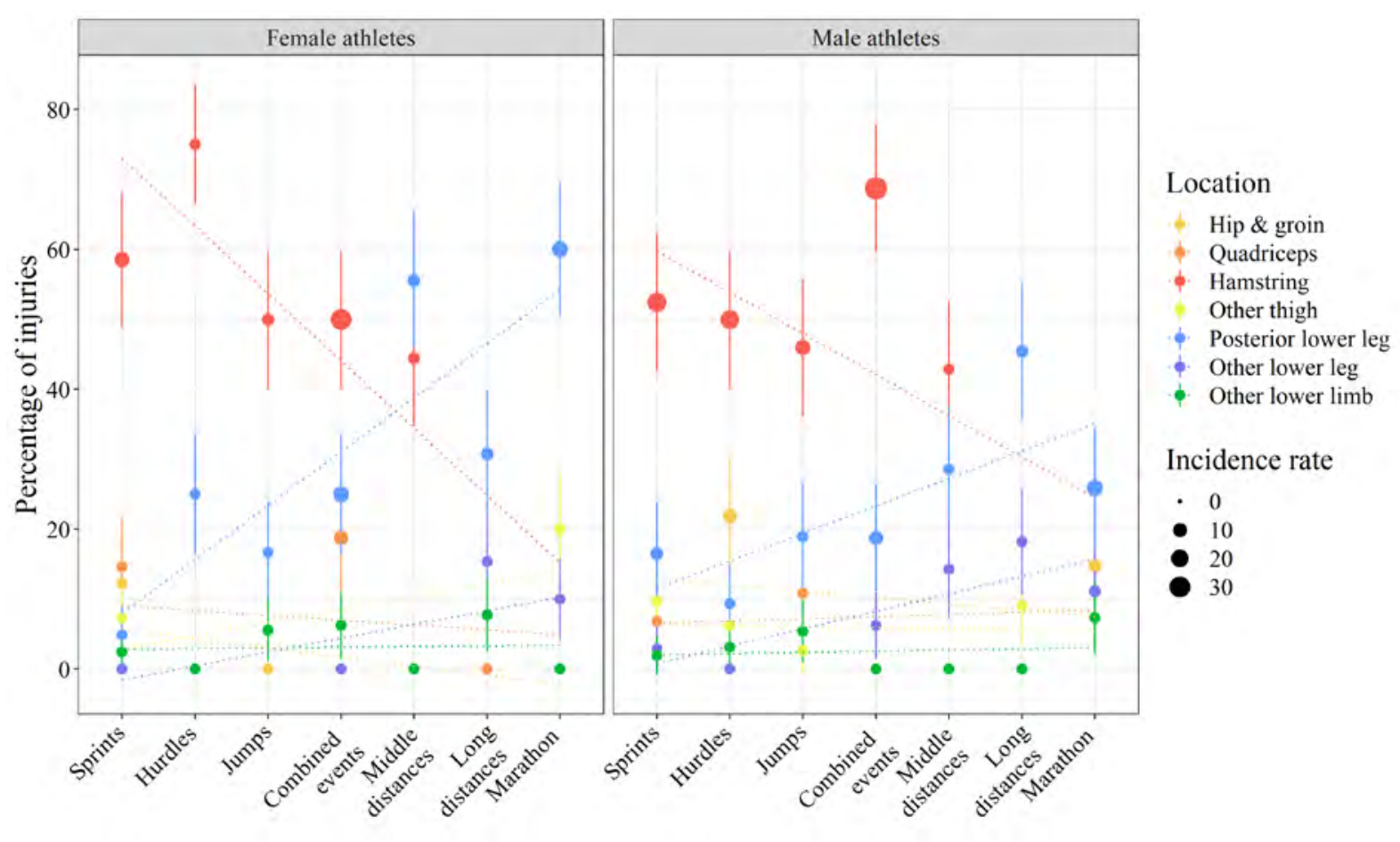


1 Figure 2 Number of in-competition lower limb muscle injuries injuries per 1000

2 competing athletes (A) and per 1000 starts (B) represented by the size of the half-disc,

3 according to sex (female athletes are represented by the up-half-disc and male athletes by the

4 down-half-disc), injury location in ordinate axis, athletics disciplines in abscissa axis, and

5 severity (visualized by colour presenting the injury burden from no time-loss in green to 600

6 estimated days of time loss per 1000 registered athletes in purple), during 13 international

7 athletics championships 2009-2019.

8
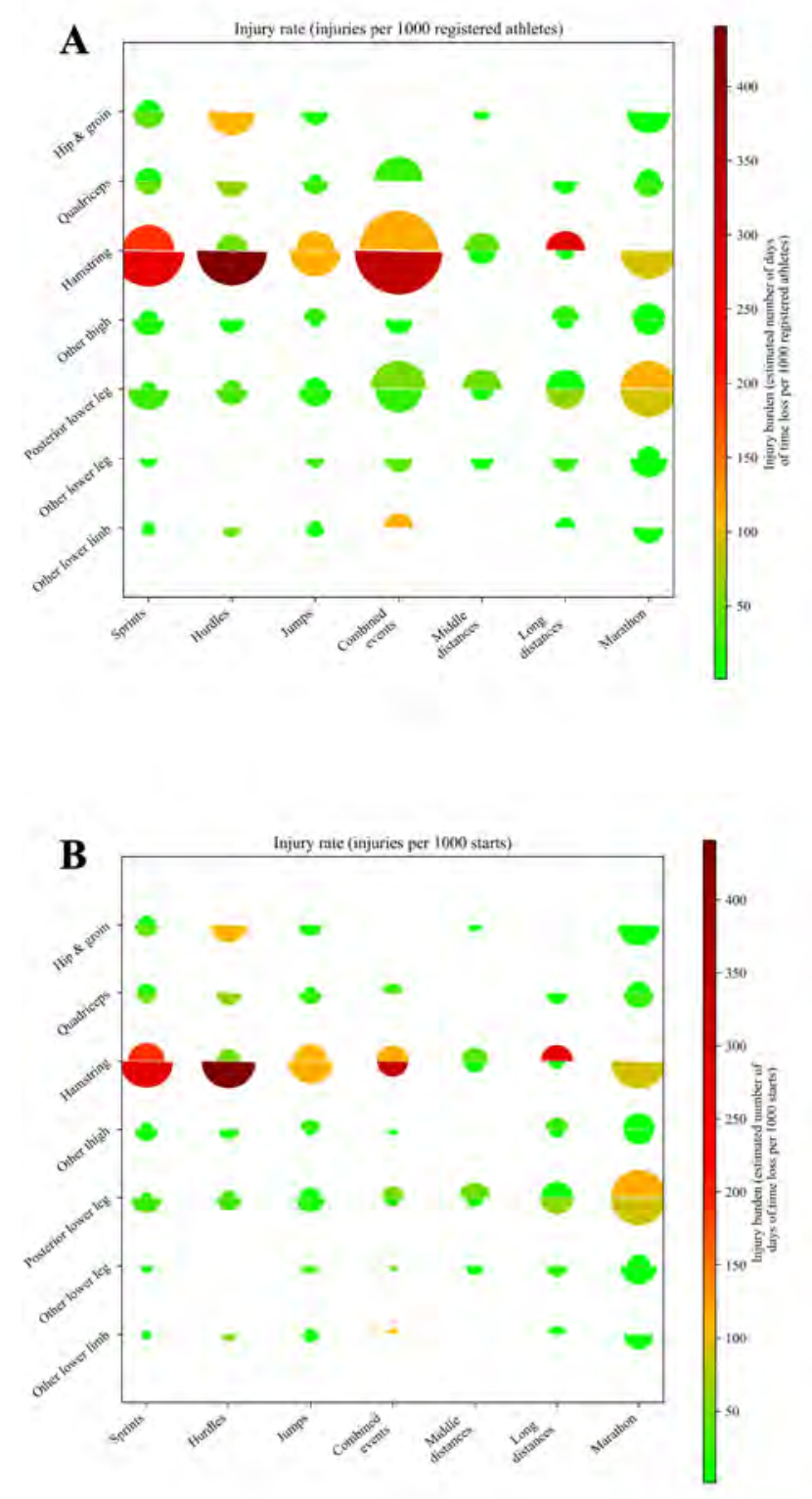
Table 1: Comparisons of injury incidence rates (i.e. number of injuries per 1000 registered athletes) and of injury burden (i.e. estimated number of days of absence from sport per 1000 registered athletes) during 13 international athletic championships 2009-2019: i) between in-competition hamstring and posterior lower leg muscles injuries for each discipline, and ii) for hamstring and posterior lower leg muscles injuries between disciplines with sprints as reference using relative risk (with $97.5 \%$ confidence intervals due to the two comparisons). Significant differences are highlighted in bold.

\begin{tabular}{|c|c|c|c|c|c|c|c|}
\hline & Sprints & Hurdles & Jumps & Combined events & $\begin{array}{c}\text { Middle } \\
\text { distances }\end{array}$ & Long distances & Marathon \\
\hline \multicolumn{8}{|c|}{$\begin{array}{l}\text { Relative risk of injury incidence } \\
( \pm 97.5 \% \mathrm{CI})\end{array}$} \\
\hline \multicolumn{8}{|c|}{$\begin{array}{l}\text { Hamstring } v s \text {. posterior lower leg } \\
\text { muscle injuries (hip as reference) }\end{array}$} \\
\hline Female athletes & $\begin{array}{l}12.00(2.31 \text { to } \\
62.30)\end{array}$ & 3.00 (0.23 to 39.73) & $\begin{array}{l}3.00(0.68 \text { to } \\
13.32)\end{array}$ & $2.00(0.51$ to 7.78$)$ & $\begin{array}{l}0.80(0.18 \text { to } \\
3.58)\end{array}$ & $\begin{array}{l}1.00(0.21 \text { to } \\
4.85)\end{array}$ & NA \\
\hline Male athletes & $3.18(1.71$ to 5.90$)$ & 5.33 (1.31 to 21.72$)$ & $\begin{array}{l}2.43(0.89 \text { to } \\
6.62)\end{array}$ & 3.67 (0.86 to 15.59$)$ & $\begin{array}{l}1.50(0.19 \text { to } \\
11.56)\end{array}$ & $\begin{array}{l}0.20(0.02 \text { to } \\
2.32)\end{array}$ & $\begin{array}{l}1.00(0.30 \text { to } \\
3.28)\end{array}$ \\
\hline \multicolumn{8}{|c|}{$\begin{array}{l}\text { Hamstring muscle injuries between } \\
\text { disciplines (sprints as reference) }\end{array}$} \\
\hline Female athletes & $1.00(0.53$ to 1.90$)$ & 2.72 (0.69 to 10.67$)$ & $\begin{array}{l}1.78(0.74 \text { to } \\
4.25)\end{array}$ & 0.42 (0.17 to 1.03$)$ & $\begin{array}{l}2.14(0.64 \text { to } \\
7.14)\end{array}$ & $\begin{array}{l}1.77(0.53 \text { to } \\
5.92)\end{array}$ & NA \\
\hline Male athletes & 1.00 (0.65 to 1.53$)$ & 01.07 (0.57 to 2.00 ) & $\begin{array}{l}1.98(1.07 \text { to } \\
3.68)\end{array}$ & 0.67 (0.32 to 1.39$)$ & $\begin{array}{l}7.35(1.95 \text { to } \\
27.65)\end{array}$ & $\begin{array}{l}17.77(21.86 \text { to } \\
170.1)\end{array}$ & $\begin{array}{l}1.67(0.68 \text { to } \\
4.07)\end{array}$ \\
\hline \multicolumn{8}{|c|}{$\begin{array}{l}\text { Posterior lower leg muscle injuries } \\
\text { between disciplines (sprints as } \\
\text { reference) }\end{array}$} \\
\hline Female athletes & 1.00 (0.11 to 9.38$)$ & 0.68 (0.04 to 10.53$)$ & $\begin{array}{l}0.44(0.06 \text { to } \\
3.43)\end{array}$ & $0.07(0.01$ to 0.48$)$ & $\begin{array}{l}0.14(0.02 \text { to } \\
0.93)\end{array}$ & $\begin{array}{l}0.15(0.02 \text { to } \\
1.03)\end{array}$ & $\begin{array}{l}0.07(0.01 \text { to } \\
0.43)\end{array}$ \\
\hline Male athletes & 1.00 (0.47 to 2.15$)$ & $1.79(0.44$ to 7.26$)$ & $\begin{array}{l}1.52(0.56 \text { to } \\
4.13)\end{array}$ & $0.78(0.19$ to 3.13$)$ & $\begin{array}{l}3.47(0.65 \text { to } \\
18.46)\end{array}$ & $\begin{array}{l}1.12(0.36 \text { to } \\
3.48)\end{array}$ & $\begin{array}{l}0.52(0.19 \text { to } \\
1.42)\end{array}$ \\
\hline
\end{tabular}




\begin{tabular}{|c|c|c|c|c|c|c|c|}
\hline $\begin{array}{l}\text { Relative risk of inj } \\
( \pm 97.5 \% \mathrm{CI})\end{array}$ & & & & & & & \\
\hline \multicolumn{8}{|c|}{$\begin{array}{l}\text { Hamstring vs. posterior lower leg } \\
\text { muscles injuries (hip as reference) }\end{array}$} \\
\hline Female athletes & $\begin{array}{l}9.76(6.67 \text { to } \\
14.26)\end{array}$ & $1.48(0.79$ to 2.75$)$ & NA & 2.21 (1.11 to 4.43$)$ & $\begin{array}{l}0.85(0.48 \text { to } \\
1.49)\end{array}$ & $\begin{array}{l}38.75(12.56 \text { to } \\
119.5)\end{array}$ & NA \\
\hline Male athletes & $\begin{array}{l}8.57(6.49 \text { to } \\
11.33)\end{array}$ & $\begin{array}{l}12.50(7.90 \text { to } \\
19.79)\end{array}$ & $\begin{array}{l}6.65(4.06 \text { to } \\
10.90)\end{array}$ & $\begin{array}{l}14.00(5.94 \text { to } \\
32.98)\end{array}$ & $\begin{array}{l}0.45(0.14 \text { to } \\
1.51)\end{array}$ & NA & $\begin{array}{l}1.02(0.64 \text { to } \\
1.63)\end{array}$ \\
\hline \multicolumn{8}{|c|}{$\begin{array}{l}\text { Hamstring muscles injuries between } \\
\text { disciplines (sprints as reference) }\end{array}$} \\
\hline Female athletes & $1.00(0.86$ to 1.16$)$ & $3.95(2.63$ to 5.94$))$ & \begin{tabular}{|l|}
$1.74(1.41$ to \\
$2.15)$ \\
\end{tabular} & $1.63(1.10$ to 2.41$)$ & $\begin{array}{l}4.59(3.00 \text { to } \\
7.05)\end{array}$ & \begin{tabular}{|l|}
$0.69(0.57$ to \\
$0.83)$ \\
\end{tabular} & NA \\
\hline Male athletes & $1.00(0.89$ to 1.12$)$ & $0.61(0.54$ to 0.70$)$ & $\begin{array}{l}2.38(1.97 \text { to } \\
2.87)\end{array}$ & 0.81 (0.67 to 1.00$)$ & $\begin{array}{l}47.58(17.47 \text { to } \\
129.6)\end{array}$ & NA & $\begin{array}{l}2.93(2.09 \text { to } \\
4.09)\end{array}$ \\
\hline \multicolumn{8}{|c|}{$\begin{array}{l}\text { Posterior lower leg muscles injuries } \\
\text { between disciplines (sprints as } \\
\text { reference) }\end{array}$} \\
\hline Female athletes & $1.00(0.60$ to 1.67$)$ & 0.60 (0.33 to 1.09$)$ & NA & $0.37(0.19$ to 0.73$)$ & $\begin{array}{l}0.40(0.24 \text { to } \\
0.68)\end{array}$ & $\begin{array}{l}2.74(0.85 \text { to } \\
8.85)\end{array}$ & $\begin{array}{l}0.17(0.10 \text { to } \\
0.27)\end{array}$ \\
\hline Male athletes & 1.00 (0.69 to 1.46$)$ & $0.90(0.53$ to 1.51$)$ & $\begin{array}{l}1.85(1.08 \text { to } \\
3.15)\end{array}$ & $1.33(0.55$ to 3.20$)$ & $\begin{array}{l}2.52(1.22 \text { to } \\
5.20)\end{array}$ & $\begin{array}{l}0.51(0.33 \text { to } \\
0.78)\end{array}$ & $\begin{array}{l}0.35(0.23 \text { to } \\
0.53)\end{array}$ \\
\hline
\end{tabular}

NA: not applicable. 